\title{
Metal Transfer Mechanisms in Hot-Wire Gas Metal Arc Welding
}

\author{
Hot-wire polarity influences bead geometry in this process
}

\author{
BY P. P. G. RIBEIRO, R. A. RIBEIRO, P. D. C. ASSUNÇÃO, E. M. BRAGA, AND A. P. GERLICH
}

\begin{abstract}
The hot-wire gas metal arc welding (HW-GMAW) process is widely used to increase the melting rate of a secondary wire through Joule heating without significantly increasing the total heat input to the substrate. Because there is limited knowledge regarding the associated arc dynamics and its influence on bead geometry, the present study considers how these are affected by the hot-wire polarity (negative or positive), hot-wire feed rate, and hot-wire orientation using a two-factor full factorial experiment with three replicates. During welding, high-speed imaging synchronized with current and voltage acquisition to study the arc dynamics. After this, each replicated weld was cut into three cross sections, which were examined by standard metallography. The preliminary results suggest that the arc was stable within the range of process parameters studied. The arc polarity played a role on arc position relative to the hot wire, with a decrease in penetration depth observed when the arc was attracted to the hot wire.
\end{abstract}

\section{KEYWORDS}

- Hot-Wire Gas Metal Arc Welding (HW-GMAW)

- Arc Blow • Metal Transfer • Rykalin Number (Ry)

- Depth of Penetration - Finger Like Penetration

- Dilution

\section{Introduction}

Progressively higher demands for efficiency and productivity in manufacturing processes have spurred development in welding processes for new applications. Arc-based welding processes present higher productivity compared to laser-based welding technologies, due to potentially high deposition rates and versatility in joint design. This has driven the use of arc welding in critical applications, including shipbuilding (Ref. 1), lightweight transportation with dissimilar welding (Ref. 2), and hardfacing of surfaces subjected to wear (Ref. 3).

Among the welding processes used for hardfacing against erosion, hot-wire gas tungsten arc welding (HW-GTAW) is commonly used due to the advantage of high deposition and controlled dilution coupled with good penetration (Ref. 4). Other processes commonly utilized for hardfacing include plasma transferred arc (PTA), submerged arc welding (SAW) (Ref. 5), cold wire GTAW, tandem gas metal arc welding (GMAW) (Ref. 6), and laser cladding (Ref. 7). However, laser-based processes are less common due to lower productivity and high costs associated with operation and maintenance of equipment.

Hot-wire gas metal arc welding (HW-GMAW) is another promising technology used for welding and hardfacing applications. It is characterized by higher deposition and versatility along with low operational costs. The core advantage of HWGMAW for overlays are the characteristics that allow reduced nominal heat input with increased deposition. This stems from the decoupling of heat input and deposition by introducing a secondary welding wire, which is resistively heated. Another important feature of these processes is their inherently lower dilution (Ref. 8), and this can help to suppress dissolution of carbides in Ni- and Fe-based composite overlays.

Although HW-GMAW can be easily used for overlays where low dilution is needed, few studies are available in the literature dealing specifically with the process characteristics and their influence on the final bead shape. In particular, the interactions between process parameters remain largely unreported. For instance, fundamental features such as thermal efficiency of HW-GMAW are unknown. Most of the applications of this process do not consider this important parameter, and few reports are available that describe successful welding parameters. The net result of this lack of information is an underutilization of HW-GMAW for structural applications.

The objective of the present study was to detail the influence of the hot-wire polarity (hot-wire negative or positive), 

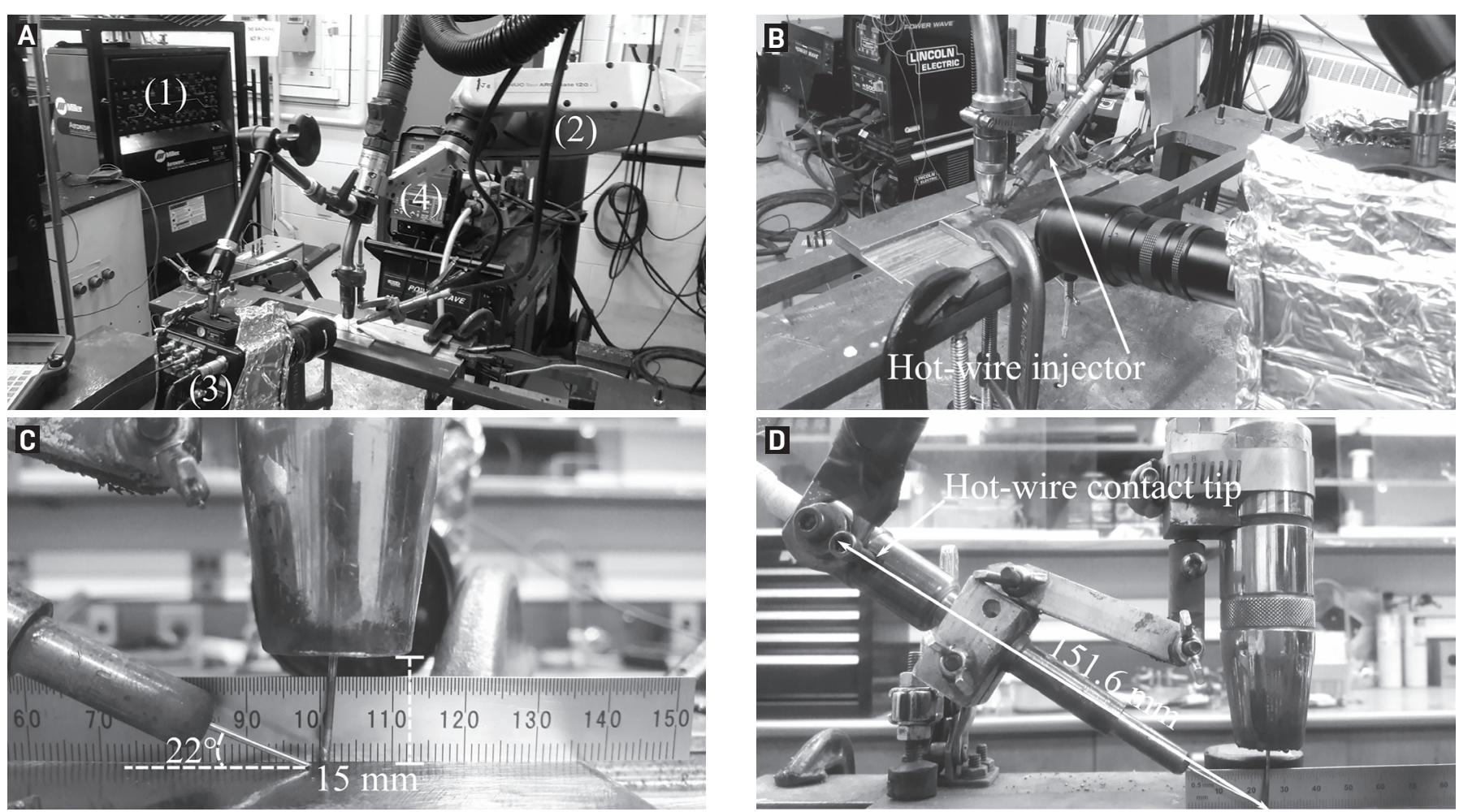

Fig. 1- Experimental set-up: A - General view with numbers indicating (1) hot-wire power source, (2) FANUC robotic arm, (3) high-speed camera, and (4) hot-wire feeder; B - detail showing the hot-wire injector; $C$ - detail showing CTWD (mm) and hot-wire angle; $D$ - the distance of the contact tip to the weld pool.

welding direction (hot-wire pushing or pulling the weld pool), and hot-wire feed rates (as a percentage of the main electrode wire feed rate). The role of these hot-wire parameters was examined for the overall stability of the welding process, arc dynamics, metal transfer mode, and consequent geometry of the final bead shape.

\section{Experimental Methodology}

\section{Welding Parameters and Experimental Set-Up}

Sections of $\%$-in.-thick (9.5-mm) AISI 1020 steel were used

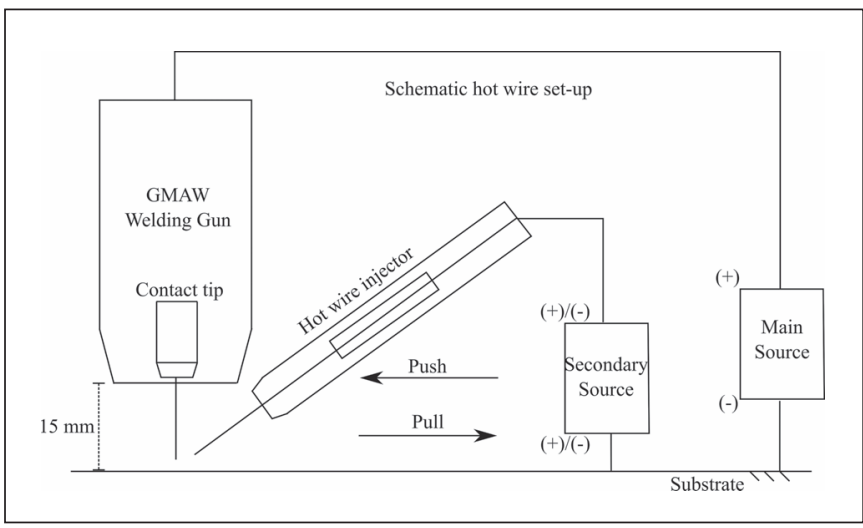

Fig. 2 - Schematic of the HW-GMAW set-up, indicating the weld directions push (hot-wire trailing the arc) and pull (hotwire leading the arc). as base metal for bead-on-plate welds. The wires used were ER70S-6 (Ref. 9) with diameters of 1.2 and $0.9 \mathrm{~mm}$ for the electrode and hot-wire, respectively.

The welds were deposited with a Lincoln Electric Power Wave ${ }^{\circledR}$ R500 used for robotic welding as the main electrode power source and a Miller Electric Aerowave welding power source as the hot-wire (secondary) power source. A robotic arc welding system was used to perform the welds, which incorporates a FANUC ARC Mate $120 i$ arm, equipped with a BINZEL VTS 500 gun. The wire feeders used were Lincoln $10 \mathrm{R}$ wire drive systems integrated to the robotic arm. During the experiments, the main source was operated in the constant voltage (CV) mode, while the hot-wire source was

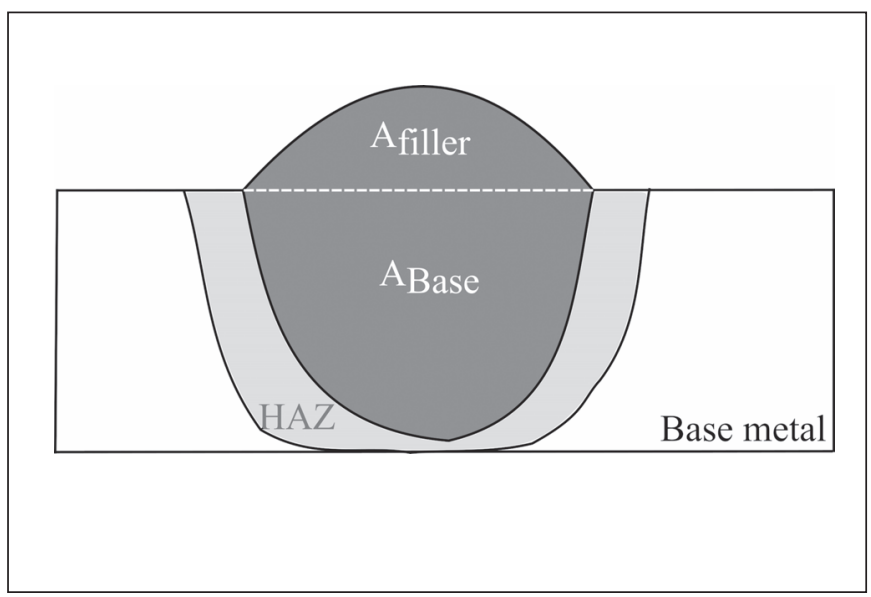

Fig. 3 - Schematics for dilution calculations. 

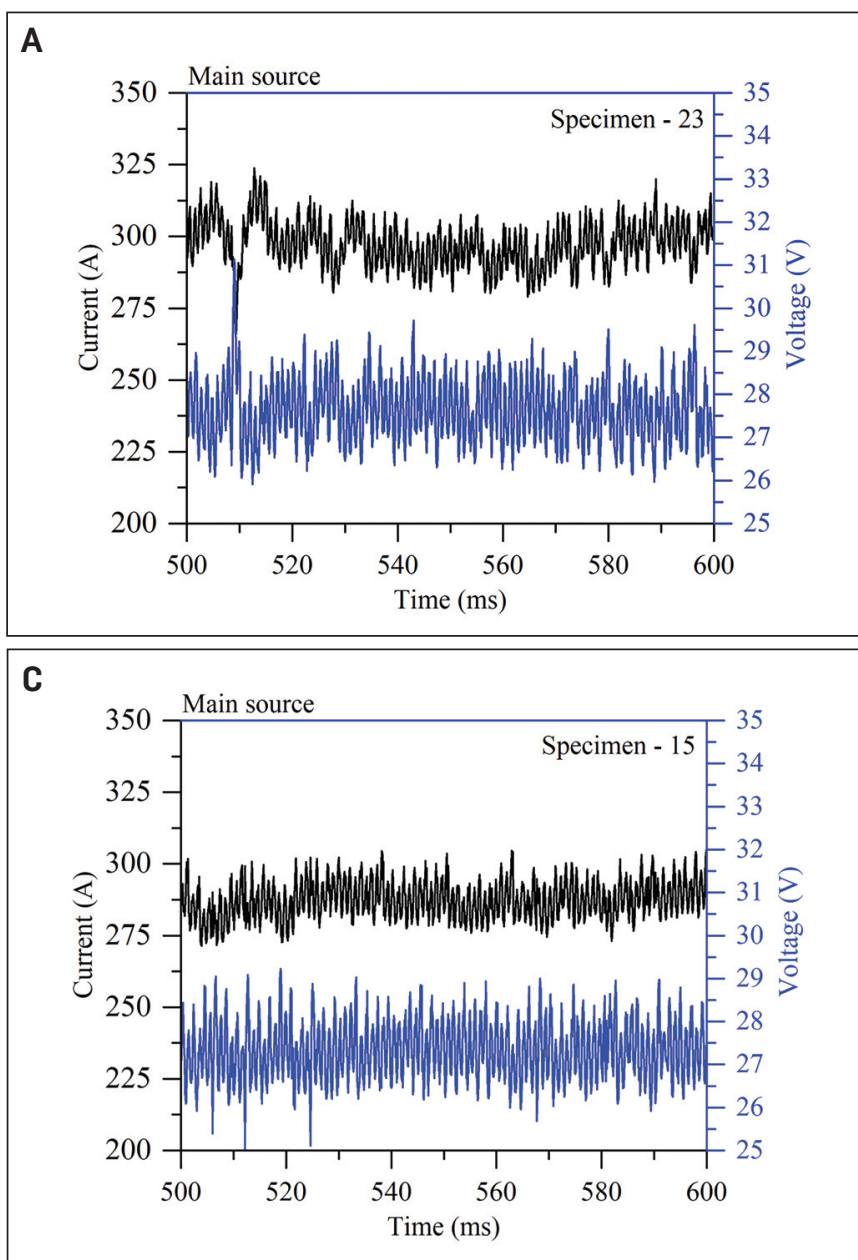

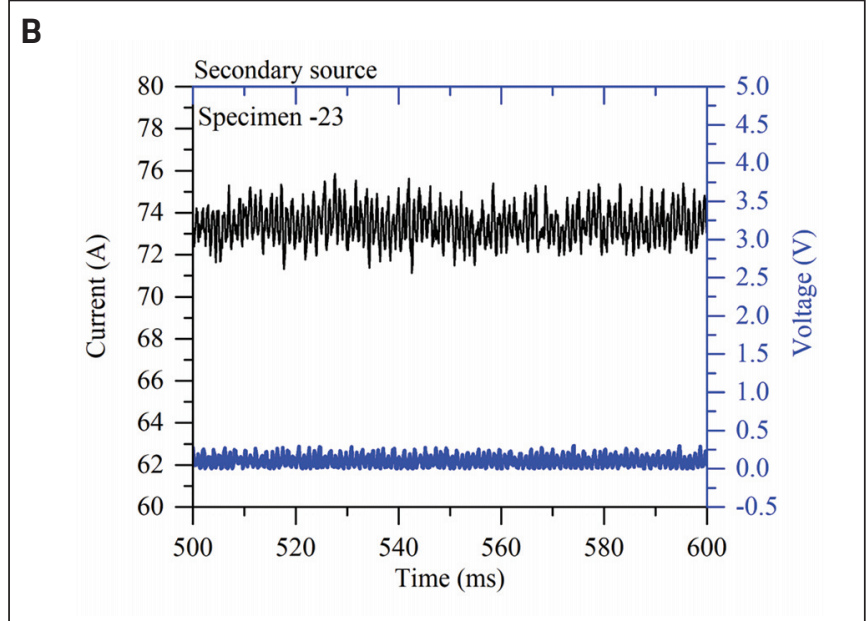

D

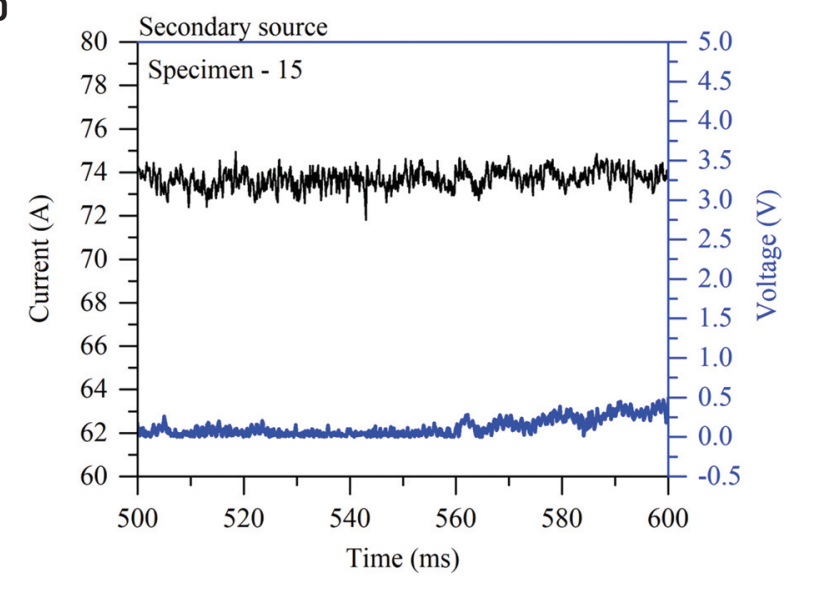

Fig. 4 - Current/voltage signals of the main source and the secondary source comparing two different specimens: A and B Specimen 23 (run \#l, negative polarity, pull, 20\%); C and D - specimen 15 (run \#3, negative polarity, pull, 100\%).

kept in the constant current (CC) mode. The polarity of the hot wire (HW) was changed to either positive or negative during the experiments to study its effect on metal transfer. The HW contact point was kept constant and equal to 151.6 $\mathrm{mm}$ (Fig. 1D) from the substrate. Figure $1 \mathrm{~A}$ and $\mathrm{B}$ show the experimental set-up used to investigate the metal transfer. During all the experiments, the HW angle of $22 \mathrm{deg}$ and contact tip to work distance (CTWD) of $17 \mathrm{~mm}$ were kept constant. Figure $1 \mathrm{C}$ shows the nozzle-to-workpiece distance (NTWD), which was $15 \mathrm{~mm}$.

Figure 2 shows a schematic of the experimental set-up highlighting the welding directions, push and pull. In the first case, the HW pushed the weld pool, while in the second case, it pulled the weld pool. It is important to emphasize the welding gun angle was kept straight (90 deg to the plate) throughout the experiments.

During the experiments, current and voltage were logged at $10 \mathrm{kHz}$ for $2 \mathrm{~s}$ for the main wire and hot wire. The voltage of the main source was measured as the difference of potential between the welding gun and the substrate, and the current of the main source was measured through the ground cable using a Hall sensor. On the other hand, the voltage on the hot wire was measured as the difference of potential the between the hot-wire contact tip (shown in Fig. 1D) and the substrate; the current in the hot wire was measured through the ground cable of the secondary welding power source. The ground connections of the main and secondary power sources were connected to the substrate. The values of current and voltage measured for both welding power sources are reported as absolute values.

In parallel, synchronized high-speed imaging was employed to study the electric arc dynamics. The videos were taken at $5000 \mathrm{fps}$, with a shutter speed of $25 \mu$ s using a band pass filter of $900 \pm 10 \mathrm{~nm}$. The average voltage $(\bar{U})$, current $(\bar{I})$, and power $(\bar{P})$ reported in this work were calculated using the following equations as reported by Joseph et al. (Ref. 10):

$$
\begin{aligned}
& \bar{U}=\frac{1}{n} \sum_{i=1}^{n} U_{i}(t) \\
& \bar{I}=\frac{1}{n} \sum_{i=1}^{n} I_{i}(t)
\end{aligned}
$$



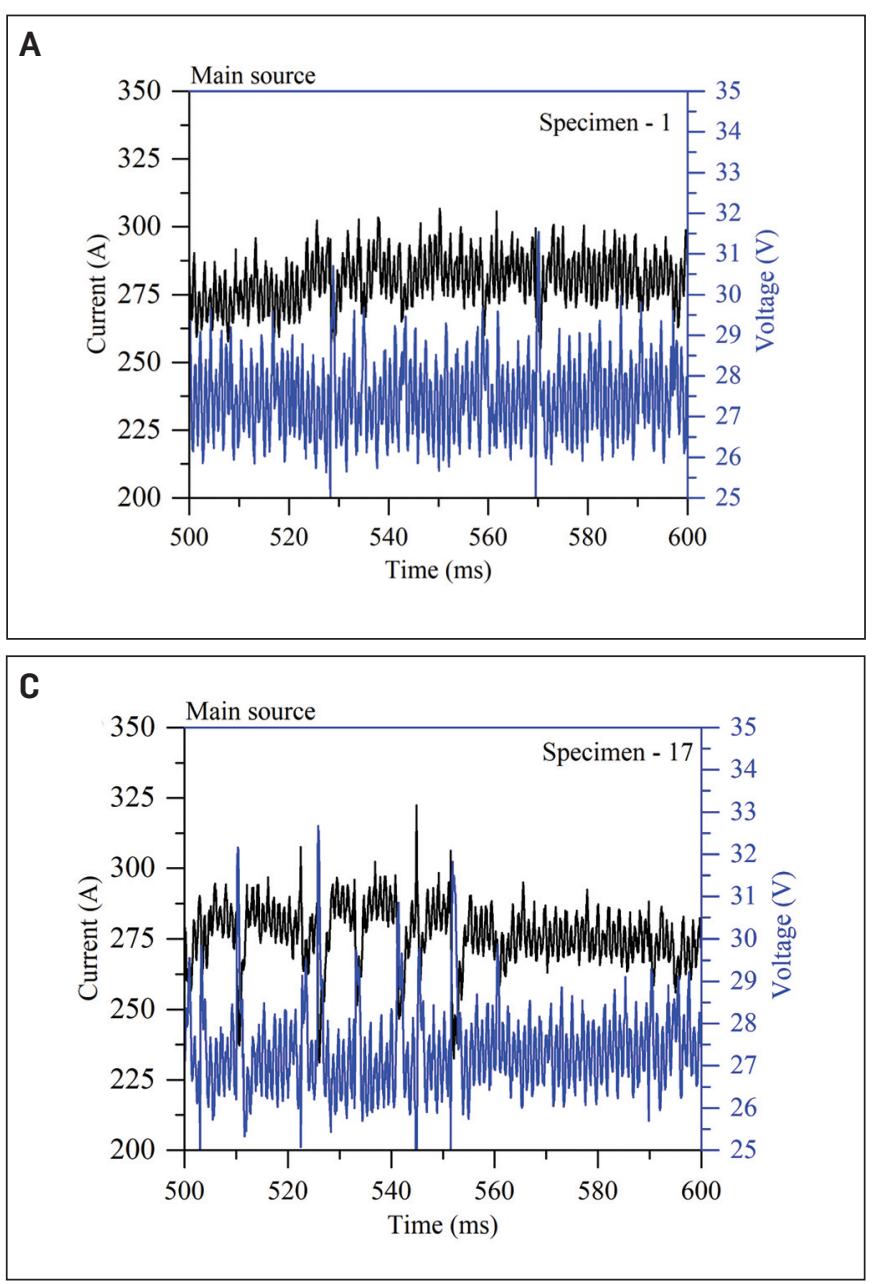

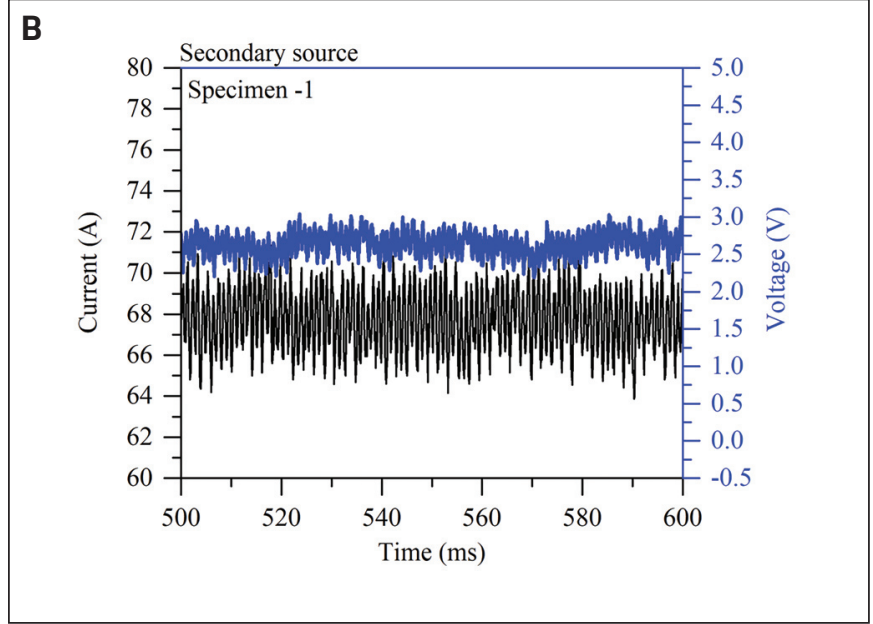

D

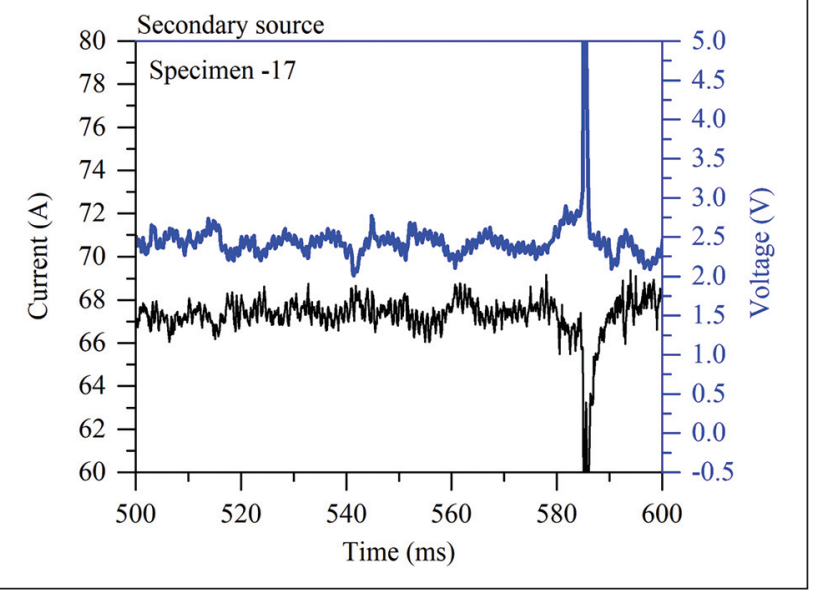

Fig. 5 - Current/voltage signals of the main source and the secondary source comparing two different specimens: $A$ and $B-$ Specimen 1 (run \#2, positive polarity, pull, 20\%); C and D - specimen 17 (run \#4, positive polarity, pull, 100\%).

$$
\bar{P}=\frac{1}{n_{i}} \sum_{i=1}^{n} U_{i}(t) \cdot I_{i}(t)
$$

where $U_{i}, I_{i}$ represent the instantaneous values of voltage and current, respectively; while $n$ represents the number of current and voltage measurements.

Table 1 presents the values of parameters under variation in this study, namely, HW polarity, HW mass rate (\%), and welding direction, while other values were kept constant. It should be noted that 20 and $100 \%$ hot-wire feed rates are equivalent to deposition rates of 0.96 and $4.80 \mathrm{~kg} / \mathrm{h}$, respectively. For all welding conditions, three replicates were taken to determine the reproducibility of the observed phenomena.

The shielding gas used was $\mathrm{Ar}-15 \% \mathrm{CO}_{2}$ at a flow of 40 $\mathrm{ft}^{3} / \mathrm{h}(19 \mathrm{~L} / \mathrm{min})$. The HW mass rate was calculated as a percentage of the main wire feed rate. The parameters chosen gave a natural spray transfer associated with high current and arc power. The polarity of the HW was manually changed by reversing the position of the connecting wires in the HW source terminals and was checked using a standard multimeter. The value chosen for the HW nominal current was set to avoid completely melting the hot-wire or arcing between the two wires and consequent damage of the HW power supply. During welding, the behavior of the main source did not appear to have been influenced by the secondary HW source.

\section{Metallography and Dilution Measurements}

After welding, all three replicates were sectioned into thirds, resulting in nine cross sections that were examined for each welding condition. After standard metallographic polishing procedures, consisting of final polishing with $1 \mu \mathrm{m}$ alumina polishing, all nine cross sections were etched with $2 \%$ Nital solution to reveal macro and microstructures. Figure 3 shows a schematic of a weld cross section.

Dilution was calculated using Equation 4 and is reported as an average following examination of nine cross sections.

$$
D=\frac{A_{\text {base }}}{A_{\text {base }}+A_{\text {filler }}}
$$



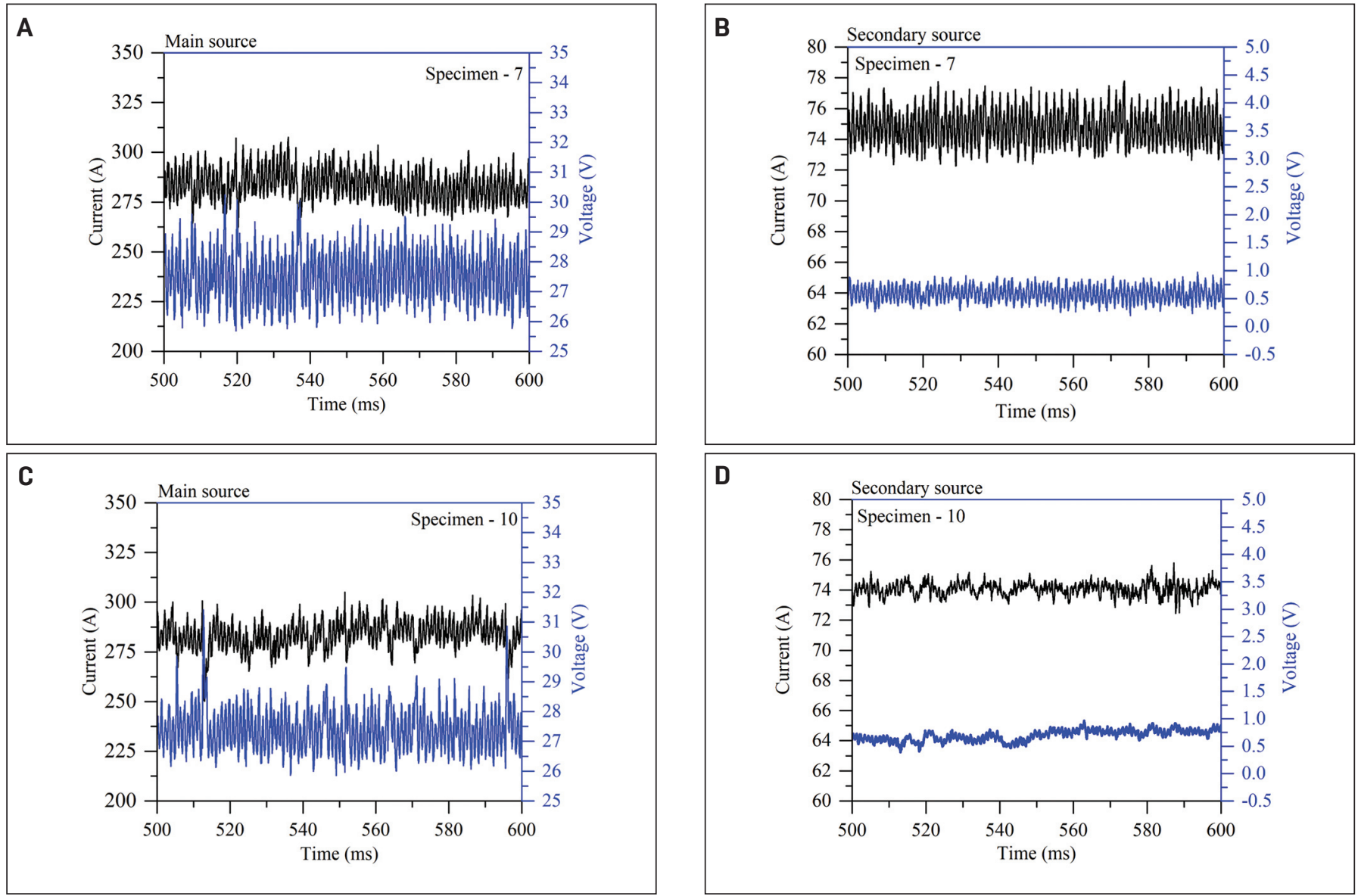

Fig. 6 - Current/voltage signals of the main source and the secondary source comparing two different specimens: A and B Specimen 7 (run \#5, negative polarity, push, 20\%); C and D - specimen 10 (run \#7, negative polarity, push, 100\%).

\begin{tabular}{|c|c|c|c|c|c|c|c|c|}
\hline $\begin{array}{c}\text { Run } \\
\#\end{array}$ & $\begin{array}{c}\text { WFS } \\
\text { (in./min) } \\
\text { [m/min] }\end{array}$ & $\begin{array}{c}\text { U } \\
\text { (V) }\end{array}$ & $\begin{array}{c}\text { Travel } \\
\text { Speed } \\
\text { (in./min) } \\
\text { [cm/min] }\end{array}$ & $\begin{array}{l}\mathrm{HW} \\
\text { Nominal } \\
\text { Current } \\
\text { (A) }\end{array}$ & $\begin{array}{c}\text { HW } \\
\text { Polarity }\end{array}$ & $\begin{array}{c}\text { HW } \\
\text { Mass } \\
\text { Rate } \\
\text { (\%) } \\
\text { [in./min] } \\
\text { \{m/min\} }\end{array}$ & $\begin{array}{l}\text { Welding } \\
\text { Direction }\end{array}$ & $\begin{array}{c}\text { Specimens } \\
\text { Codes }^{*}\end{array}$ \\
\hline 1 & $\begin{array}{c}350 \\
{[8.89]}\end{array}$ & 28 & $\begin{array}{c}25 \\
{[63.5]}\end{array}$ & 70 & Negative & $\begin{array}{c}20 \\
{[124]} \\
\{3.15\}\end{array}$ & Pull & $23,24,25$ \\
\hline 2 & 350 & 28 & 25 & 70 & Positive & 20 & Pull & $1,2,3$ \\
\hline 3 & 350 & 28 & 25 & 70 & Negative & $\begin{array}{c}100 \\
{[622]} \\
\{15.8\}\end{array}$ & Pull & $13,14,15$ \\
\hline 4 & 350 & 28 & 25 & 70 & Positive & 100 & Pull & $17,18,19$ \\
\hline 5 & 350 & 28 & 25 & 70 & Negative & 20 & Push & $7,8,9$ \\
\hline 6 & 350 & 28 & 25 & 70 & Positive & 20 & Push & $4,5,6$ \\
\hline 7 & 350 & 28 & 25 & 70 & Negative & 100 & Push & 10, 11, 12 \\
\hline 8 & 350 & 28 & 25 & 70 & Positive & 100 & Push & $20,21,22$ \\
\hline 9 & 350 & 28 & 25 & 70 & - & - & - & $26,27,28$ \\
\hline
\end{tabular}

*Specimens for which the videos were captured are noted in bold. 

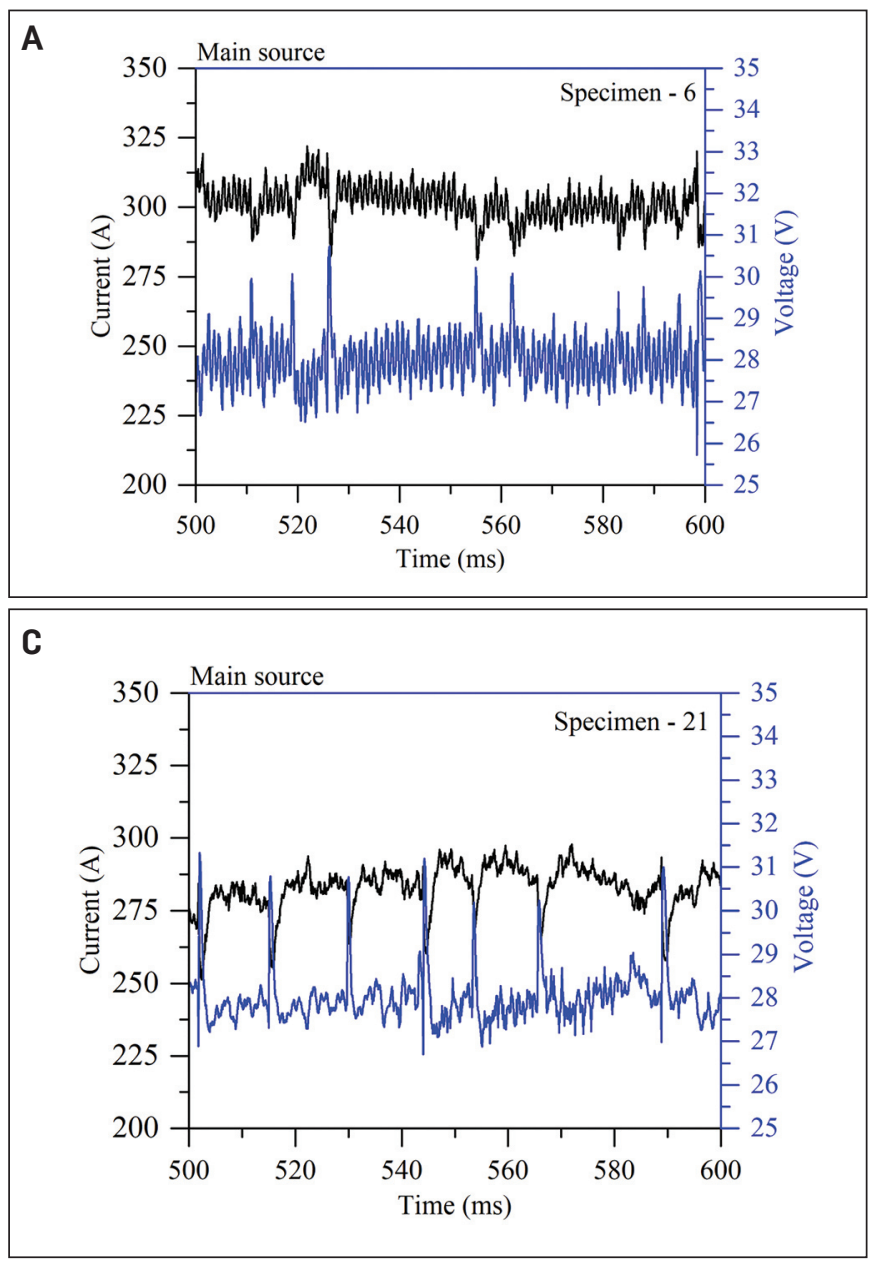
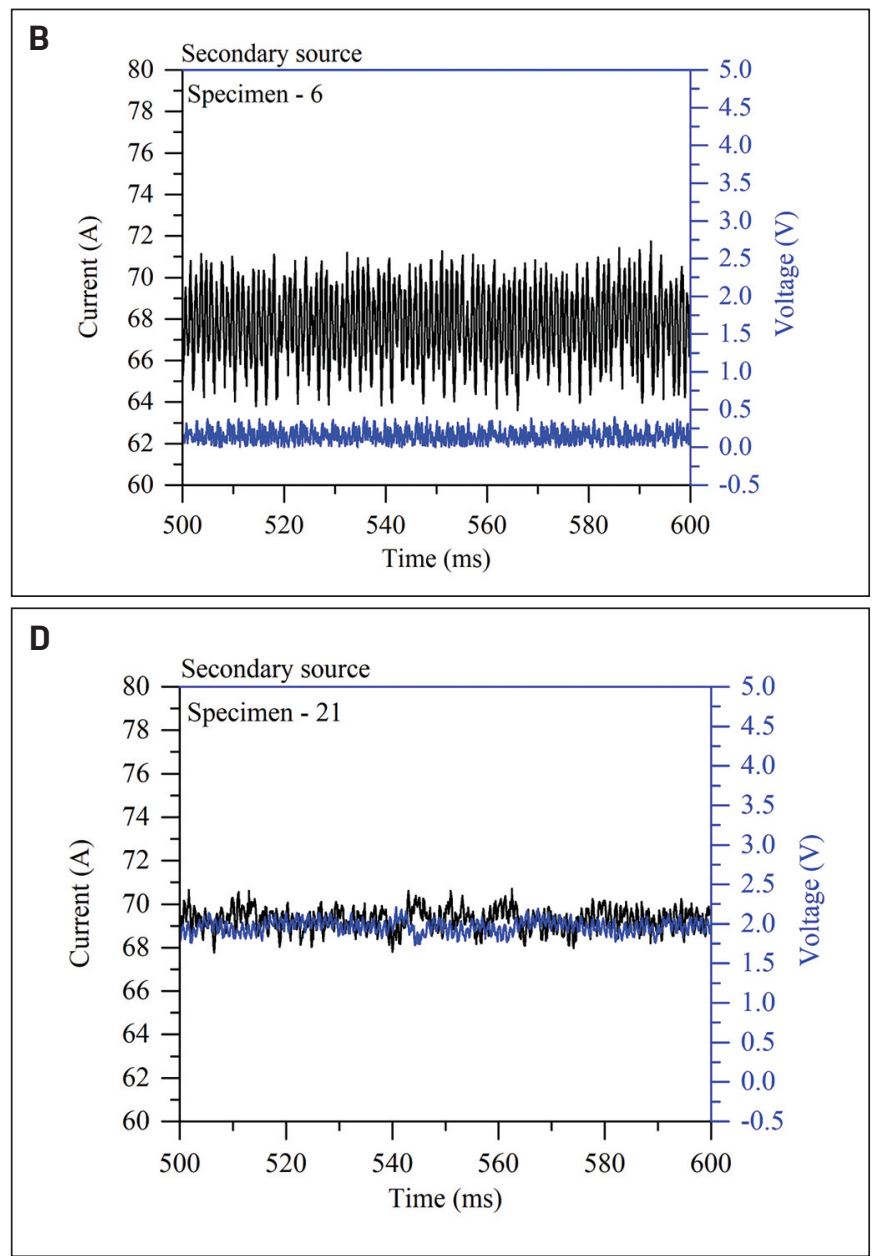

Fig. 7 - Current/voltage signals of the main source and the secondary source comparing two different specimens: A and B Specimen 6 (run \#6, positive polarity, push, 20\%); $C$ and D- specimen 21 (run \#8, positive polarity, push, 100\%).

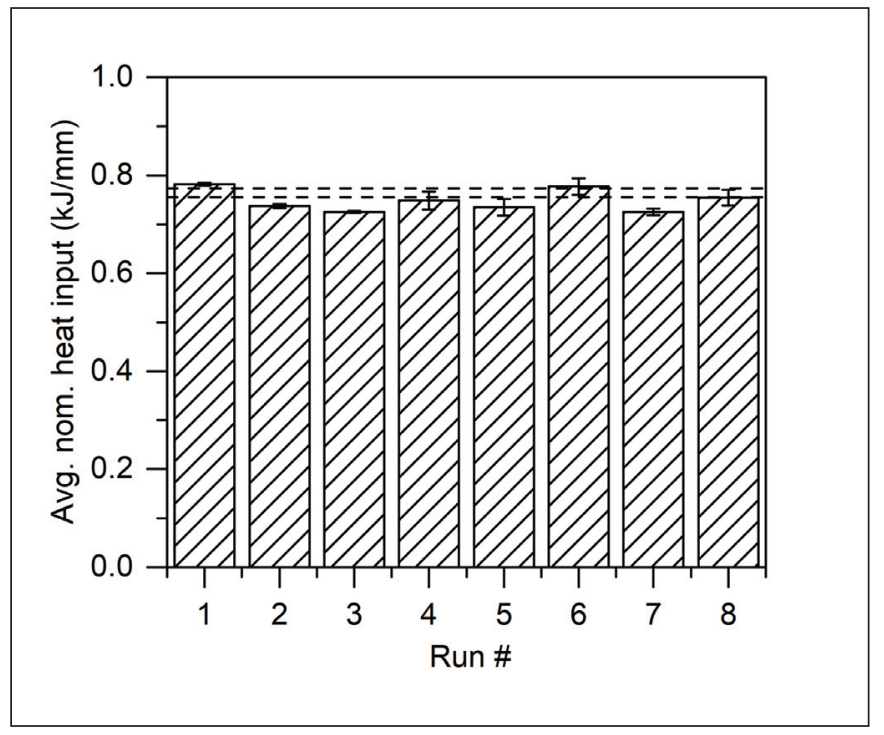

Fig. 8 - Average total nominal heat input between the specimens of an experimental run. The dashed lines indicate the range of variation of the standard GMAW. The total heat input is calculated from the total power, which is the sum of the electrode power and hot-wire power.

\section{Results and Discussions}

\section{Current/Voltage Signals}

All the experiments utilized a main electrode feed rate of $350 \mathrm{in.} / \mathrm{min}$, a main source voltage of $28 \mathrm{~V}$, a travel speed of $25 \mathrm{in.} / \mathrm{min}$, and a hot-wire nominal current of $70 \mathrm{~A}$. The only variables that were changed were welding direction (pull or push), HW feed rate (20 or 100\%), and HW polarity (negative or positive). Only the variables that emphasize the difference in the observed results will be discussed in this section.

Figure 4 shows the voltage/current signals comparing the role of the hot-wire feed rate in specimen 23 (negative polarity, pull, 20\%) and specimen 15 (negative polarity, pull, $100 \%$ ), such that these two specimens involve the same hotwire voltage. However, comparing Fig. 4 with specimens 1 and 17 (which correspond to negative vs. positive HW polarity) shown in Fig. 5, the voltage applied in the secondary source changes from an average of 0.092 and $0.208 \mathrm{~V}$, respectively, when using negative polarity of 2.62 and $2.46 \mathrm{~V}$, respectively, with positive $\mathrm{HW}$ polarity.

Summarizing these results, when one compares specimens 23 and 15, which have negative polarity, to specimen 


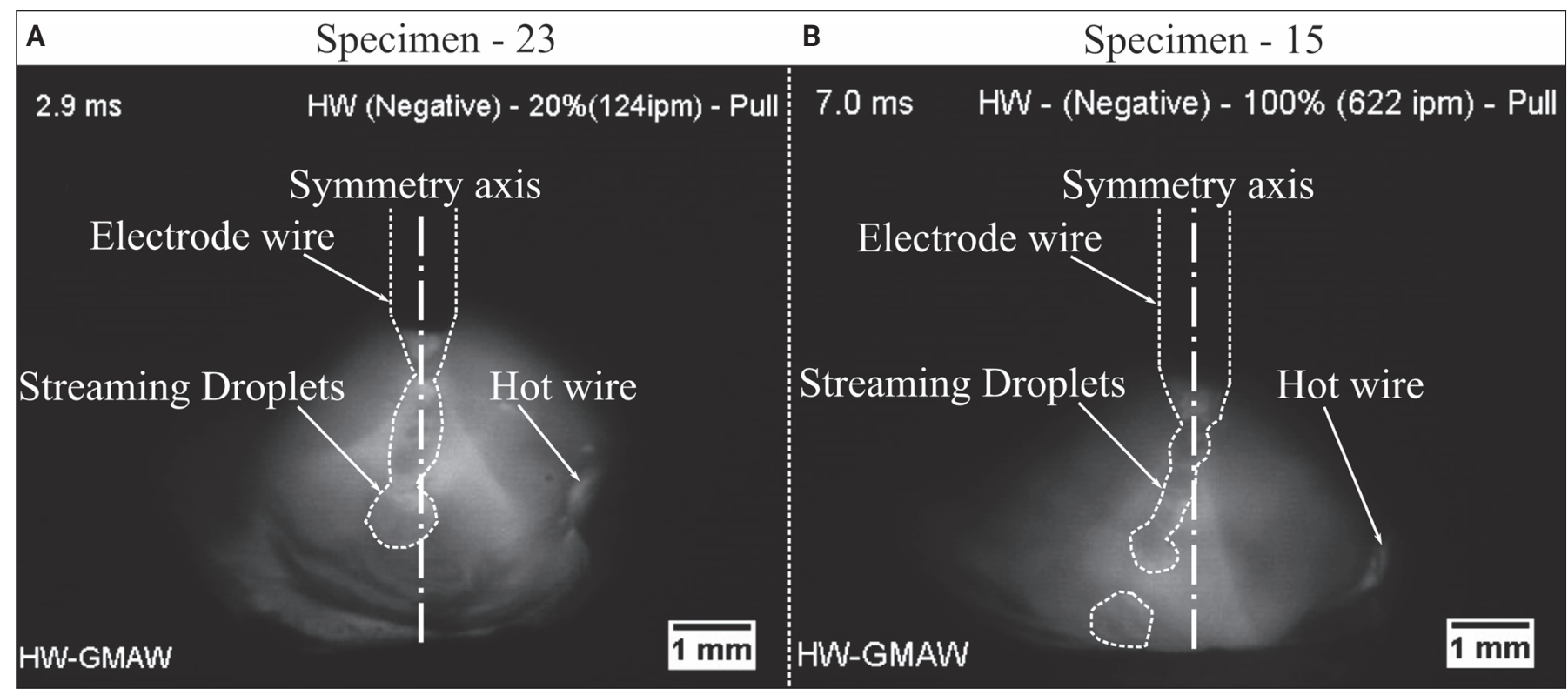

Fig. 9 - Hot-wire GMAW metal transfer: A - Specimen 23 (negative polarity, pull, 20\%); B - specimen 15 (negative polarity, pull, 100\%). (Note: $\mathrm{ipm}=$ in./min.)

17 (which uses positive polarity, pull, and $100 \%$ ), it is clear a different hot-wire polarity causes a difference in measured voltage. Comparing Figs. 4 and 5, it can be seen that the former situation is more stable than the latter based on the larger fluctuations and transient behavior observed in the voltage, in particular, possibly due to the higher HW feed rate in specimen 15 , which might stabilize the wandering of the cathode spots in the weld pool, accounting for superior arc stability.
Comparing specimen 7 (negative polarity, push, 20\%) and specimen 10 (negative polarity, push, 100\%) in Fig. 6, it can be seen that though the secondary source responds similarly, the current and voltage amplitude in it are higher in specimen 7 than in specimen 10 . The basic difference between these is the hot-wire feed rate. In specimen 10 , the higher fraction of hotwire stabilized the response of the secondary source, accounting for the lower amplitude variability of current and voltage; the mechanism can be explained in prior work (Ref. 11).

\begin{tabular}{|c|c|c|c|c|c|c|c|}
\hline Run & Specimen & $\begin{array}{l}\text { Inst. Avg. } \\
\text { Current } \\
\text { (A) }\end{array}$ & $\begin{array}{l}\text { Inst. Avg. } \\
\text { Voltage } \\
\text { (V) }\end{array}$ & $\begin{array}{l}\text { Inst. Avg. } \\
\text { Power } \\
\text { (W) }\end{array}$ & $\begin{array}{l}\text { Nom. Heat } \\
\text { Input } \\
(\mathrm{kJ} / \mathrm{mm})\end{array}$ & $\begin{array}{l}\text { Avg. Nom. } \\
\text { Heat Input } \\
(\mathrm{kJ} / \mathrm{mm})\end{array}$ & $\begin{array}{l}\text { Standard } \\
\text { Deviation } \\
(\mathrm{kJ} / \mathrm{mm})\end{array}$ \\
\hline 9 & 26 & 295.1 & 27.5 & 8113 & 0.767 & & \\
\hline (Standard GMAW) & 27 & 290.3 & 27.5 & 7988 & 0.755 & 0.76 & 0.009 \\
\hline
\end{tabular}

Table 3 - Percentage of Total Power Due to Hot-Wire Joule Heating Dissipation

\begin{tabular}{cccc} 
Experimental Runs \# & Hot-Wire Avg. Inst. Power (W) & Total Power (W)* & Power Ratio (\%) ${ }^{\star *}$ \\
\hline 1 & 4 & 8242 & 0.05 \\
2 & 177 & 7804 & 2.26 \\
3 & 10 & 7676 & 0.14 \\
4 & 167 & 7922 & 2.11 \\
5 & 20 & 7778 & 0.25 \\
6 & 2 & 8224 & 0.03 \\
7 & 36 & 7675 & 0.46 \\
8 & 146 & 7085 & 2.06 \\
\hline
\end{tabular}




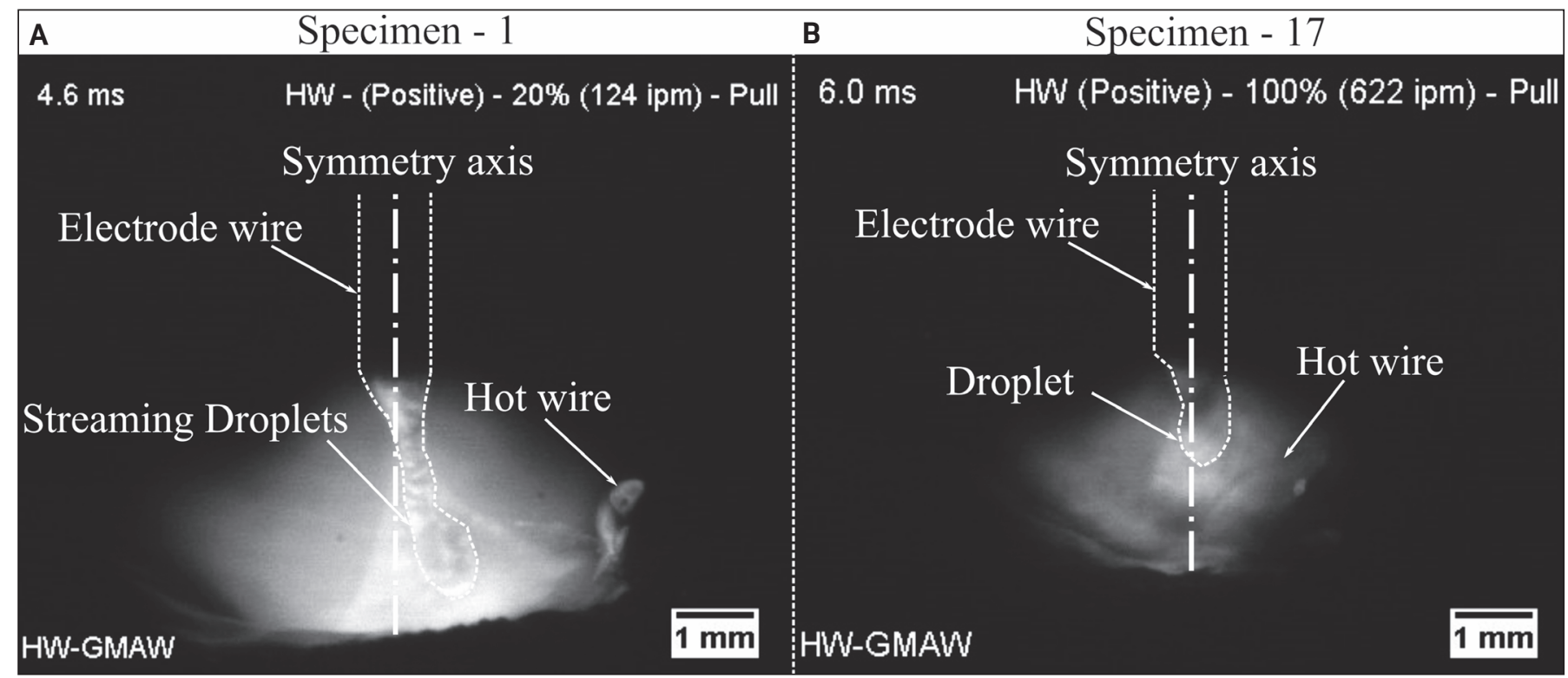

Fig. 10 - Hot-wire GMAW metal transfer across the arc: A - Specimen 1 (positive polarity, pull, 20\%); B - specimen 17 (positive polarity, pull, 100\%). (Note: ipm = in./min.)

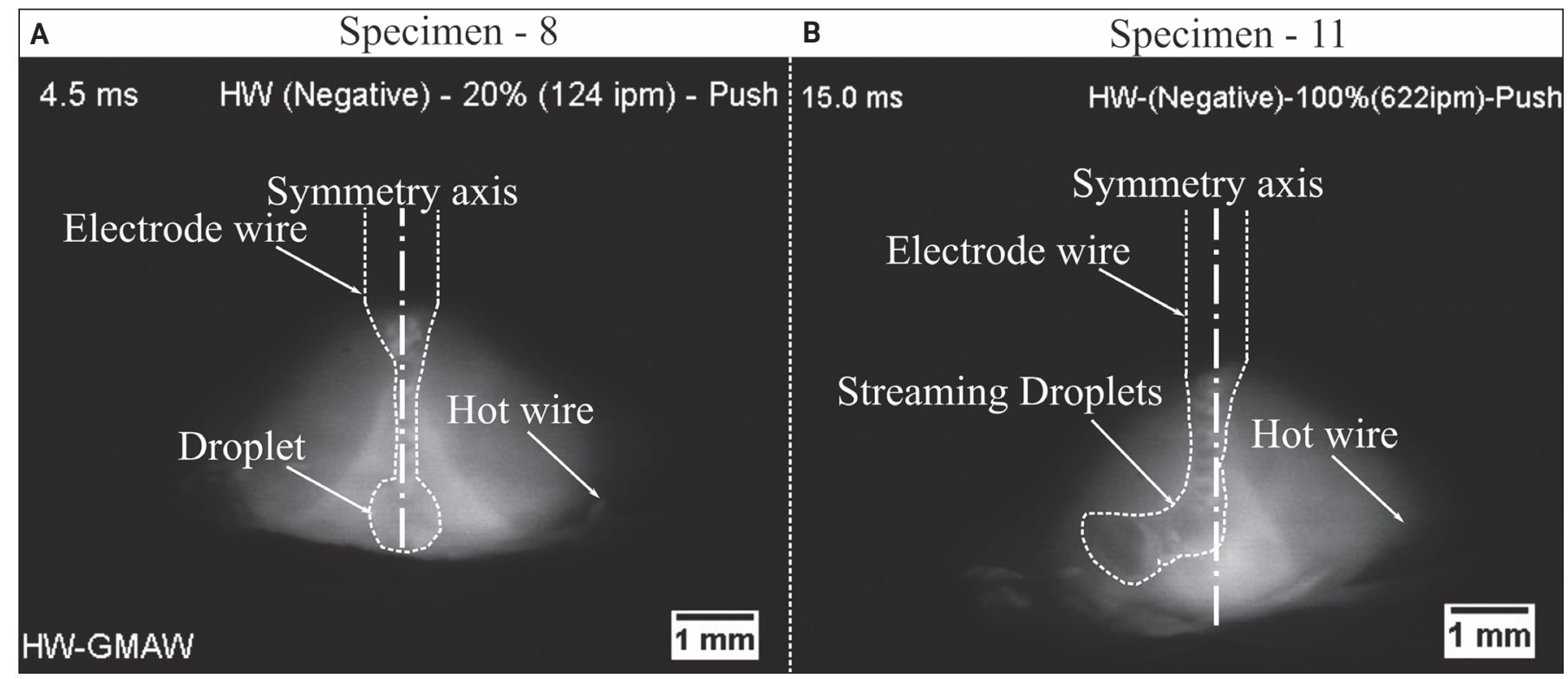

Fig. 11 - Hot-wire GMAW metal transfer across the arc: A - Specimen 8 (negative polarity, push, 20\%); B - specimen 11 (negative polarity, push, 100\%). (Note: ipm = in./min.)

Comparing specimens 6 (positive polarity, push, 20\%) and 21 (positive polarity, push, 100\%), refer to Fig. 7. It can be noted that by increasing the hot-wire feed rate while using positive polarity in the push orientation, the output is dominated by sudden variations in current and voltage. This is due to the intermittent contact of the electric arc with the hot-wire, which causes brief changes in the arc attachment locations or length.

Comparing the effect of polarities in Figs. 4 and 5, hot-wire negative polarity provides a more stable arc than when hotwire positive polarity is used, as can be inferred from the variation of current and voltage in the secondary source, as well as the sudden variations of current and voltage in the main source. This is probably due to the fact that a negative hot wire repels the arc, avoiding short circuits. Comparing the stability for different hot-wire feeding orientations in Figs. 4 and 6, it appears when the hot wire is pushing, the welding pool is more unstable than when the hot-wire is pulling it.

When placing the hot-wire in the pushing orientation, there is a tendency to push the welding pool or to submerge the wire below it, rather disturbing the cathode spots wandering on its surface. Conversely, when the hot-wire is in the pulling orientation in front of the weld pool, there is a tendency for the weld pool to be stretched and the hot-wire droplets be transferred more easily than when pushing it. Again, when the addition of hot-wire increases, the stabilization of the cathode spots (electron emitting sites) can be observed due to cooling of the weld pool (Ref. 12), which results in a more sta- 


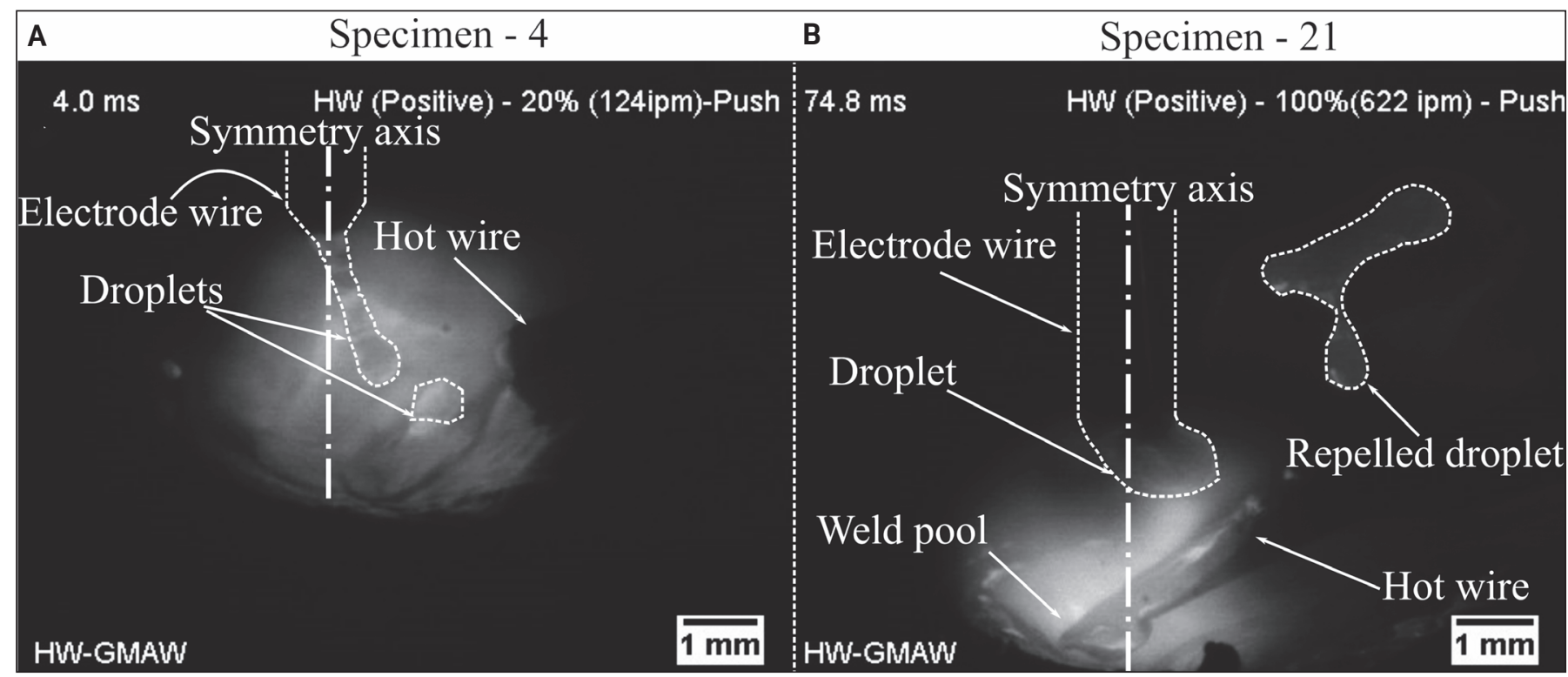

Fig. 12 - Hot-wire GMAW metal transfer across the arc: A - Specimen 4 (positive polarity, push, 20\%); B - specimen 21 (positive polarity, push, $100 \%)$. (Note: ipm = in./min.)

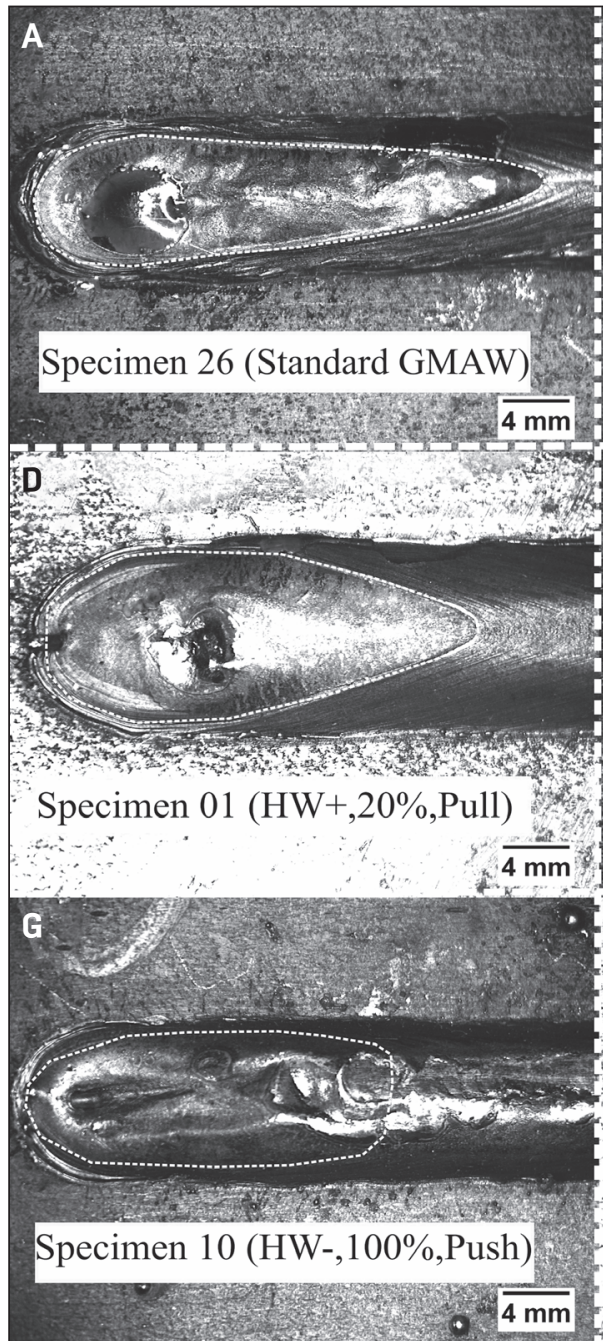

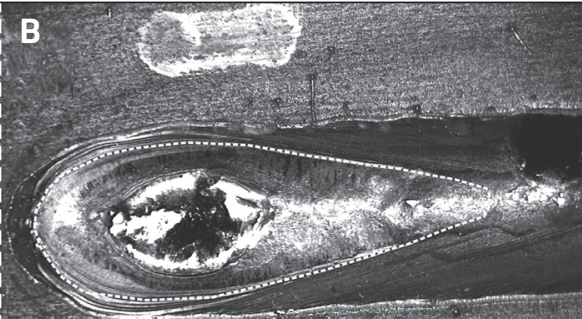

Specimen 23 (HW-, 20\%,Pull)

E

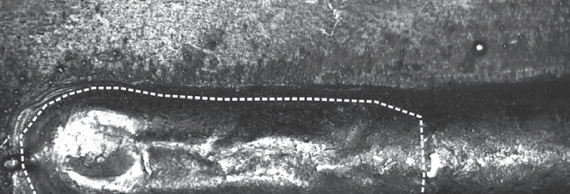

$17(\mathrm{HW}+, 100 \%, \mathrm{Pull})$ Specimen $17(\mathrm{HW}+, 100 \%$, Pull $)$

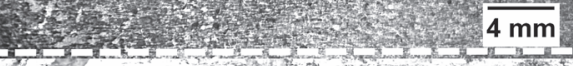

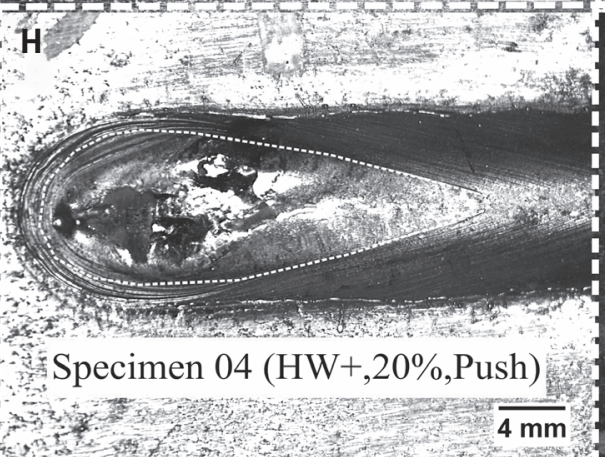

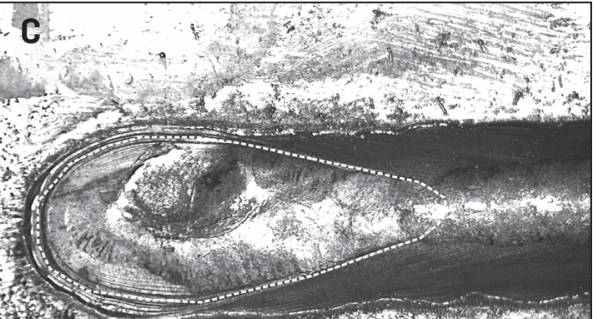

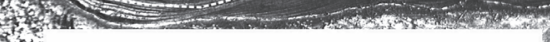

Fiv Specimen $15(\mathrm{HW}-, 100 \%$, Pull)
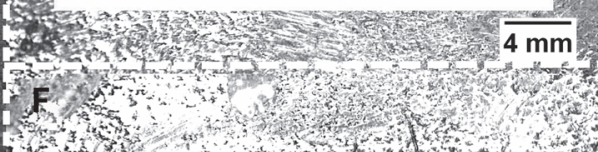

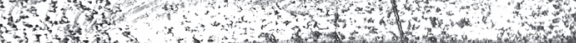
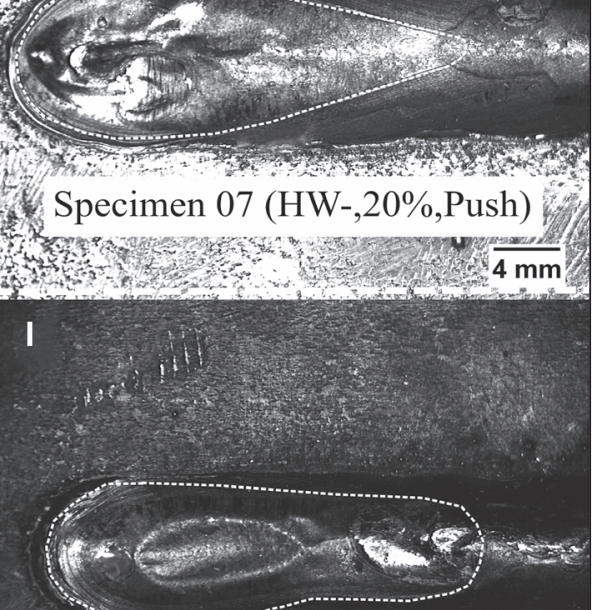

Specimen $21(\mathrm{HW}+, 100 \%$, Push)

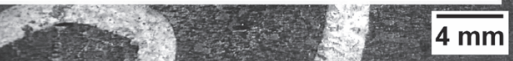

Fig. 13 - Representative bead aspects for these produced welds: A - Standard GMAW; B-I - HW-GMAW. For all the conditions WFS = $350 \mathrm{in.} / \mathrm{min}, \mathrm{U}=28 \mathrm{~V}, \mathrm{TS}=25 \mathrm{in} . / \mathrm{min}$, and CTWD = $17 \mathrm{~mm}$. Hot-wire feeding is $20 \%$ (124 in./min) and $100 \%$ (622 in./min). 

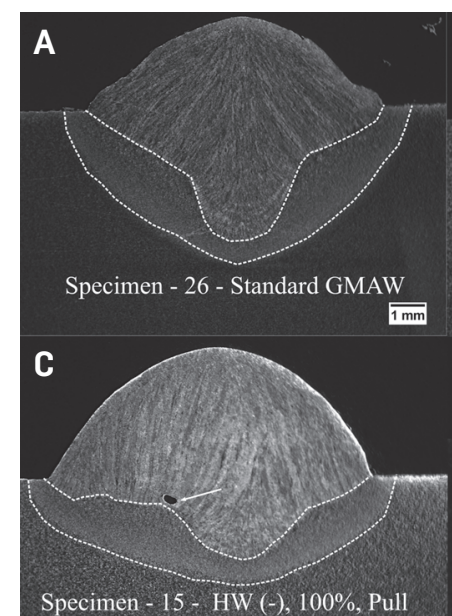

$1 \mathrm{~mm}$

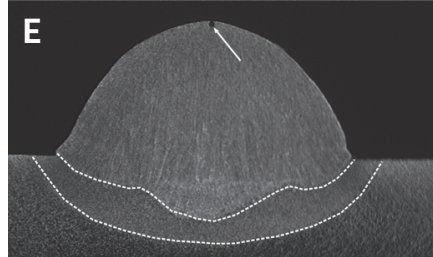

Specimen - 17 - HW (+), 100\%, Pull

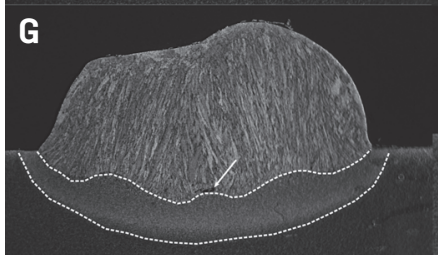

Specimen - 10 - HW (-), 100\%, Push

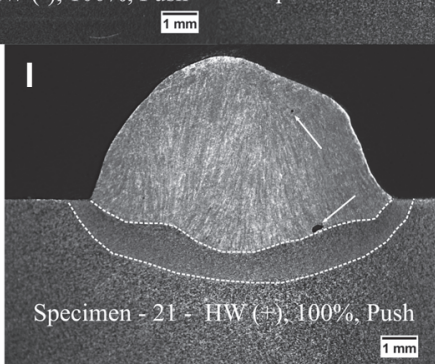

Fig. 14 - Representative cross sections for the welds manufactured. The arrows indicate discontinuities in the cross sections. Specifically, the arrow in C indicates an inclusion; in $E$ indicates porosity; in G indicates an inclusion; and in I indicates an inclusion (upper arrow) and porosity (lower arrow). The conditions of each specimen are embedded in each cross section.

ble arc signal (current and voltage response).

It can be seen that the nominal heat input calculated as the instantaneous arc power $(\mathrm{kJ} / \mathrm{s})$ over travel speed $(\mathrm{mm} / \mathrm{s})$ is slightly lower for HW-GMAW, for some experimental runs, compared to standard GMAW - Fig. 8. For example, negative polarity associated with higher hot-wire feed rates produced the lowest nominal heat inputs that can be seen in runs \#3 and 7 . Both runs had negative polarity and $100 \%$ hot-wire feed rate, but operated in pull and push welding directions, respectively.

For the sake of comparison, the electrical parameters of the standard GMAW (run \#9) are given in Table 2. The average nominal heat input $(\mathrm{kJ} / \mathrm{mm})$ for all other experimental runs is given in Fig. 8. Moreover, in Fig. 8 the heat input range of standard GMAW is shown in dashed lines to facilitate the comparison between HW-GMAW and GMAW.

The discussion about the nominal heat input provides an introduction to the next section where the phenomena of metal transfer is examined further. Since different hot-wire feed rates and polarities produced similar nominal heat inputs, it is likely that only the combination of these variables affected the metal transfer, rather than one exclusive parameter.

\section{Metal Transfer Mechanisms}

The arc dynamics during HW-GMAW depend on the polarity of the hot-wire and the current in the electrode wire, which can be modelled as two cylindrical conductors. When a current passes through two cylindrical conductors with different polarities, the magnetic field induced by the current flow produces a resultant force that repels both conductors. Conversely, if the conductors have the same polarity, the resultant force tends to attract both conductors.

As expected, when the hot-wire was kept in negative polarity, the resultant force from the hot-wire current repelled the arc, as can be seen by the deflected streaming droplets in Fig. 9. For low (20\%) and high (100\%) hot-wire feed rates, the hotwire melted within the weld pool. Even at higher feed rates, the hot-wire was easily melted by the arc, due to the additional energy provided by Joule heating (Table 3).

Figure 10 indicates when the hot-wire polarity changed to positive, the arc was attracted to the hot-wire. In this case, the hot-wire still melted in the weld pool; however, when the higher hot-wire feed rate increased further, the arc was strongly attracted to the hot-wire, inducing an instantaneous reduction of arc length causing the metal transfer to momentarily become globular. Due to the self regulation of the main source operating in constant voltage mode, this reduction in arc length was counterbalanced by an increase in current to maintain the melting rate and preset arc length by compensating with voltage. This dependence of metal transfer on the arc length was also observed by Xiang et al. (Ref. 13) when studying twin GMAW.

Figure 11 shows the situation where there was only a slight repulsion of the arc by the hot-wire (specimen 8: negative polarity, push, 20\%). Due to the low hot-wire feed rate, it was easily melted and did not exert a strong influence on the arc. Conversely, when a high hot-wire feed rate was used, this strongly repelled the arc, which subsequently repelled the droplet, causing droplets to transfer toward the leading region of the weld pool as shown in Fig. 11B.

Figure 12A shows the strong attraction of the arc to the hot-wire when it was positive, and this displaced the welding pool. The hot-wire melted in the welding pool, but the arc was not pinned to the hot-wire in this situation, and the metal transfer was directed toward the back of the welding pool. In Fig. 12B, the arc was completely pinned to the hotwire, which caused a notable reduction of arc length and led to more severe short circuits, since the droplet could then touch the hot wire easily. Differences between these two transfer modes could be clearly noted in terms of the influ- 


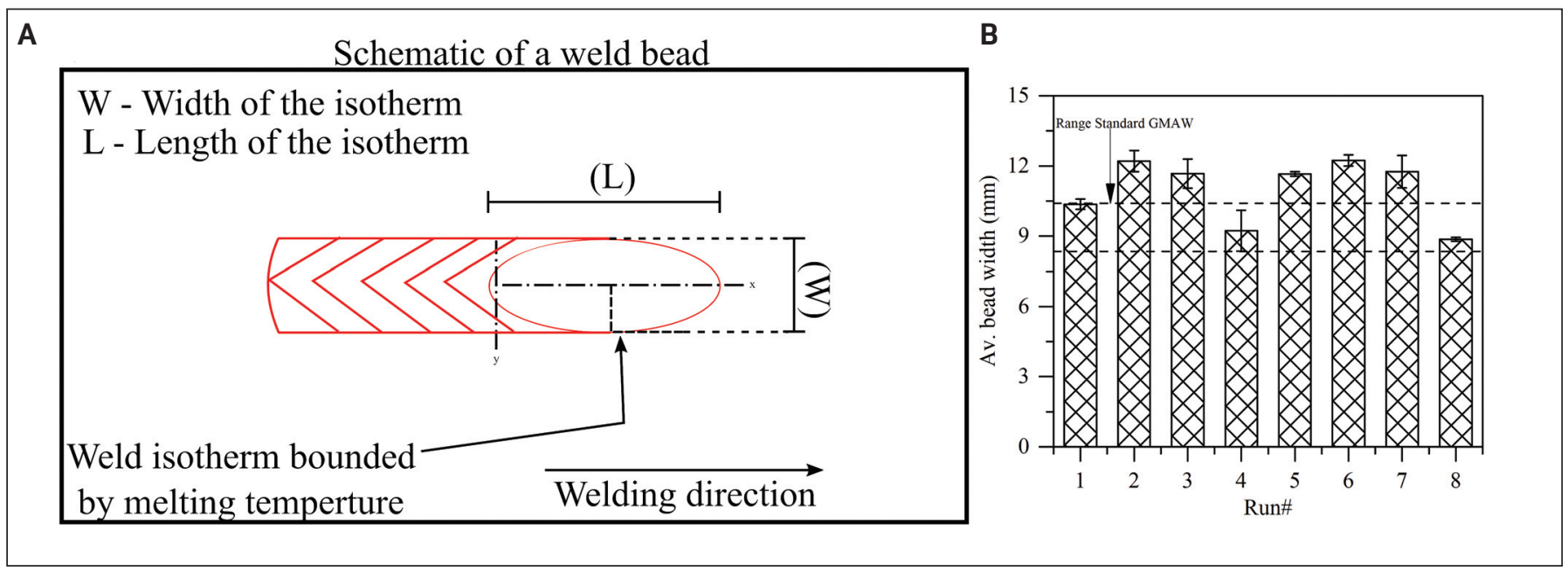

Fig. $15-A-$ Schematic showing the relationship between the maximum width of the weld pool isotherm and the bead width; $B-$ variation of bead width. The dashed line indicates the range for GMAW (run \#9).

ence on the final bead geometry. Moreover, the presence of short circuits led to an increase in spatter.

\section{Bead Profiles and Cross Sections}

Figure 13 presents the bead aspects for produced specimens. The isotherm contours (dashed lines) in the bead aspect provide evidence that the introduction of hot-wire, hotwire polarity, and weld direction changed the shape of the isotherm, consequently, varying the heat distribution in the plate. However, it is not possible to affirm that the heat transferred to the plate changed, since no calorimetric measurements were performed.

Figure 14 presents the cross sections for the manufactured welds in this study. As can be seen in Fig. 14A, the standard GMAW specimen exhibited higher penetration and dilution than those produced with HW-GMAW. The modifications induced by changing polarity, welding direction, and hot-wire feed rates led to changes in the geometry for the same value of wire feed and travel speed.

The addition of a hot-wire decreased the depth of penetration while simultaneously causing a change in the electric field near the weld pool, which either promoted repulsion or attraction of the arc to the hot-wire. It is understood that penetration is a function of the droplet momentum, which excavates the weld pool (Refs. 14, 15). If the arc is pinned to the hot wire, this acts to shield the welding pool from droplets and consequently reduces the penetration.

However, varying the polarity of the hot-wire led to increased deposition rates via the hot-wire feed and also repulsion or attraction of the arc. This repulsion or attraction of the arc moved the weld pool away or to the hotwire, and increased or suppressed the droplets touching the weld pool. Figure 14 indicates that the amount of hotwire rate exerted a more significant effect than just polarity, particularly based on Fig. 14B and G, where there was a
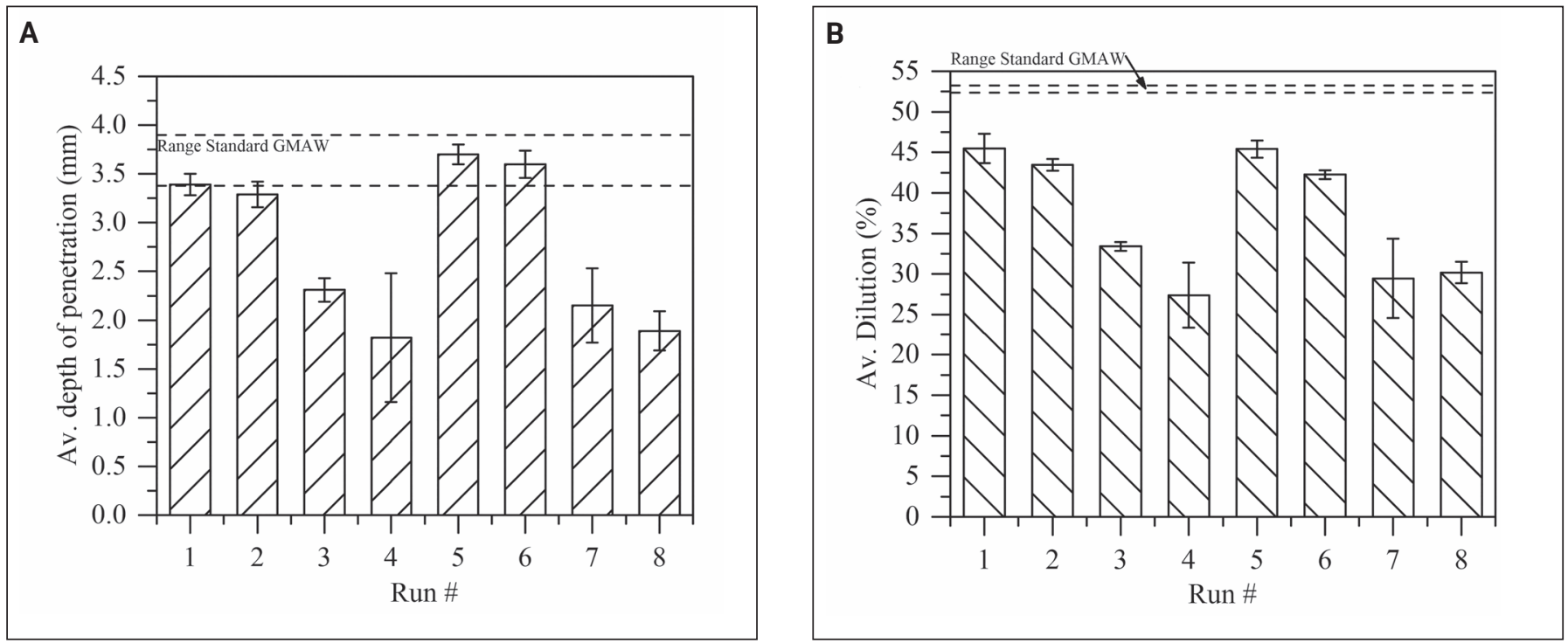

Fig. $16-A-$ Average depth of penetration for all the experimental runs; B - average dilution for all runs. The dashed line indicates the range for GMAW (run \#9). The results are an average of nine cross sections. 

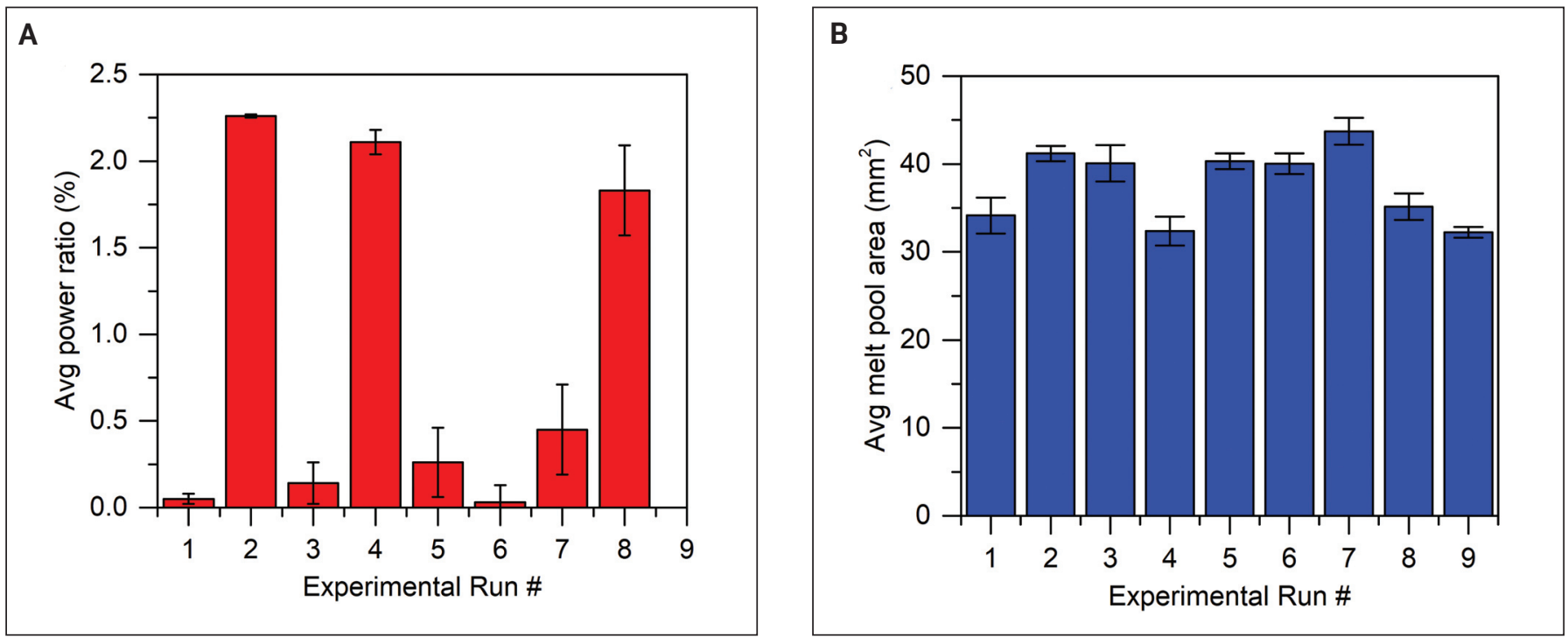

Fig. $17-A-$ Average power ratio, which is the ratio of the hot-wire Joule heating dissipated power over the total power (sum of hot wire and electrode power); B - area of the weld pool calculated through the cross sections.

difference in feed rates but the polarity was the same. On the other hand, comparing Fig. $14 \mathrm{H}$ and I, the increase in hot-wire feed rate appeared to drastically decrease penetration depth.

Another feature that can be analyzed from the weld pool aspect is a variation in the Rykalin number (Ry) (Ref. 16). This parameter is defined in Equation 5 as follows:

$$
R y=\frac{\eta Q v}{\alpha^{2} \delta h}
$$

where $\eta$ is the thermal efficiency of the welding process, $Q$ is the gross heat-input $(\mathrm{J} / \mathrm{s}), v$ is the travel speed in $(\mathrm{m} / \mathrm{s}), \alpha$ is the thermal diffusivity at the liquidus temperature in $\left(\mathrm{m}^{2} / \mathrm{s}\right)$, and $\delta h$ is the enthalpy of melting in $\left(\mathrm{J} / \mathrm{m}^{3}\right)$.

It has been proposed that this dimensionless parameter, according to Fuerschbach, is similar to the Peclet number in terms of comparing the importance of conduction and convection as the main form of heat transfer in welds (Ref. 17). According to Mendez et al. (Ref. 17), two types of heat sources can be distinguished: fast-heat sources (Regime I, $R y>1$ ) and slow-heat sources (Regime II, $R y \leq 1$ ). In fastheat sources, the heat transfer is dominated by convection, while in slow-heat sources, conduction dominates. Murray and Scotti (Ref. 14) have modelled penetration as a function of $R y$, though in their work $R y$ is referred to as $B$, the dimensionless heat transfer parameter.

The Ry number has been shown to vary with the aspect ratio $(A R)$ of the welding isotherm (Ref. 18). For Regime I, the increases are steeply in relation to the $R y$ number but remain constant for Regime II. The isotherm aspect ratio is defined as isotherm length $(L)$ over the isotherm width $(W)$, as seen in Fig. 15 and Equation 6. As the value of $W$ decreases, the value of $A R$ increases, provided that $L$ remains constant. Given that, an increase in $A R$ increases the value $R y$. Some experimental conditions in HW-GMAW suggest there is an increase in width, which causes a decrease in $R y$, for example in Fig. 13D.

$$
A R=L / W
$$

Figure 15A compares the bead width to the width of the melting temperature isotherm. Consequently, if there is a change in bead width, there are also changes in the heat transfer mode in the weld pool. Figure 15B shows the range of bead width for the standard GMAW in a dashed line; it can be determined for certain conditions the bead width increased, and consequently, so did the role of convection in heat transfer, taking into account the proportionality between bead width and Ry. The increase in convection leads to the increase in the convection currents inside the weld pool, which can improve the metal mixture inside the melt pool.

It seems that this shift in weld width is correlated to a combination of polarity and hot-wire feeding, since in runs \#2 (positive polarity, pull, 20\%) and 6 (positive polarity, push, $20 \%$ ), the width increased more on average compared to other specimens, independent of welding direction. However, more experiments are required to clarify this subject, as it has implications on melting efficiency, since it is a function of $R y$.

\section{Penetration and Dilution}

Figure 16A shows the depth of penetration for all experimental runs calculated using all specimens. The dashed lines show the range of penetration for standard GMAW specimens. Except for $20 \%$ hot-wire feed rate, all other runs had a decreased depth of penetration on average in comparison to standard GMAW. Runs \#5 and 6 had the same common welding direction and hot-wire feed rate of $20 \%$ with a push orientation, however, with negative and positive polarities, respectively.

The combination of low hot-wire feed rate and push welding orientation increases penetration. A possible mechanism is the hot-wire causes the pressure adjacent to the weld pool to increase since it pushes the melt pool, causing the molten metal to fill the weld pool cavity. Re- 
garding the other runs, all had lower penetration than the standard GMAW, which implies reduced dilution.

An attractive application of HW-GMAW appears to be weld overlays, since it offers lower heat input and dilution compared to the standard GMAW with superior deposition rates (Ref. 8). Dilution is a critical property for weld overlays, and in principle, overlays should exhibit lower dilution due to the reduced penetration rates.

Figure 16B shows the dilution for all the runs calculated using all three specimens with the range of dilution of the conventional GMAW presented in dashed lines. It can be noted for all the conditions assessed in the experimental runs, the dilution decreased compared to the standard GMAW condition. For example, introduction of a hot-wire can decrease dilution by $25 \%$ on average, considering run \#4 shown in Fig. 16B. Also, Fig. 16A and B indicate that runs \#5 and 6 had higher penetration than the lowest value of GMAW range with lower dilution compared to the GMAW range.

Meanwhile, the specimens in run \#6 exhibited slightly reduced finger-like profiles, with similar penetration to specimens in run \#5 coupled with reduced dilution - Fig. $13 \mathrm{H}$. It is suggested the polarity plays a role in the development of finger-like penetration in hot-wire welding, though further experiments are needed to clarify this matter. According to Lancaster (Ref. 19), the finger-like penetration mechanism results from a cavity formed below the weld pool, which is sustained by the plasma jet pressure. One of the forces that opposes the formation of this cavity is surface tension. Another theory explains finger-like penetration by the momentum transferred by the droplets to the center of the weld pool, which causes enhanced convection and leads to a local increase in substrate melting.

As the specimens in run \#6 were welded in positive polarity, the arc was deflected toward the hot-wire due to the interaction of their electromagnetic fields. This displacement of the arc changed the droplet path, thus attracting the droplets toward the hot-wire. However, the welds were performed with $20 \%$ HW-feed rate, which was unable to completely shield the weld pool from the droplets. The droplets were directed toward the side of the weld pool close to the wire, promoting sideways droplet impact, thus reducing the finger profile while keeping the penetration similar to specimens in run \#5.

\section{Average Power Ratio and Melt Pool Cross-Sectional Area}

Figure 17 shows the relationship for all experimental runs of the average power ratio (defined as the ratio of the hot-wire Joule dissipated power (W) over the sum of the hot wire and electrode wire power) and the area of the melt pool, taken from the cross sections. Calculating the effects, using analysis of variance (ANOVA) (Ref. 20), of hot-wire polarity, hot-wire feed rate, and hot-wire orientation, it can be identified which of those parameters plays a higher role in the area of the melt.

The highest effects governing power ratio are due to hotwire polarity and the combination hot-wire polarity and hot-wire orientation - Fig. 17A. This means that changing from negative to positive hot-wire polarity increases the power ratio, which is consistent with Fig. 17A, where runs \#2, 4, and 8 had positive polarity. This happens due to the fact that in positive polarity, the voltage of the secondary source is higher than in negative polarity, possibly due to repulsion of the arc.

The combination of hot-wire polarity and hot-wire orientation indicates that when both change to the highest levels (positive and push), the power ratio decreases (refer to runs \#5 and 6, in Fig. 17A), since again the voltage in the secondary decreases. The reason behind this is likely due to the fact that while operating in hot-wire positive, the difference of potential of the hot-wire and the electric arc decreases, since they attract each other.

Figure 17B shows the variation of weld pool area for all the experimental runs. The main effects that govern the cross-sectional area of the melt pool are hot-wire polarity, hot-wire feed rate, and hot-wire orientation combined. The ANOVA suggests the combination of hot-wire polarity and feed rate has the highest effect on increasing the area of the melt pool. This seems logical since higher feed rates increase the volume of molten metal introduced into the melt pool, and negative hot-wire polarities offer higher melting rates than positive hot-wire polarities. An example of this is run \#7 in Fig. 17B.

Comparing runs \#2, 4, and 8 in Fig. 17A, they provided the higher power ratios and all were positive hot-wire polarity, and that due to attraction of the electric arc, there was possibly an increase in difference of potential between the hot-wire and the electrode wire, which accounted for a higher power ratio. However, a higher power ratio did not necessarily reflect a higher weld pool area - Fig. 17B. This is because the hot wire introduces additional heat into the melt pool, but also increases losses to the environment, particularly when the hot-wire has higher power.

\section{Conclusions}

Standard GMAW and HW-GMAW welds were fabricated and assessed using high-speed imaging and standard metallographic procedures. Metal transfer dynamics and its implication in bead geometry and welding bead formation were analyzed. Based on the observations, the following conclusions can be drawn:

1. Hot-wire feed rates can decrease penetration up to $45 \%$ and dilution up to $25 \%$ compared to standard GMAW when HW feed rate is $100 \%$, for instance;

2. Hot-wire polarity can attract or repel the arc and, coupled with the HW feed rate, can alter bead geometry through changes in penetration depth and bead height;

3. Welding direction and hot-wire feed rates are the parameters that mostly affect the arc stability of the welding process based on the current/voltage signals for the range of parameters in this study;

4. HW-GMAW provides low values of dilution while keeping depth of penetration similar to standard GMAW, particularly when the hot-wire feed rate is $20 \%$, as for example in run \#1 (HW negative, 20\%, and pull orientation), run \#2 (HW positive, 20\%, and pull orientation), run \#5 (HW negative, 20\%, and push orientation), and run \#6 (HW positive, $20 \%$, and push orientation). For all other welding runs, the penetration is lower than in standard GMAW. 


\section{References}

1. Lezzi, F., and Costa, L. 2013. The development of conventional welding processes in naval construction. Welding International 27: 786-797. DOI: 10.1080/09507116.2012.753256

2. Mvola, B., Kah, P., Martikainen, J., and Suoranta, R. 2015. State-of-the-art of advanced gas metal arc welding processes: Dissimilar metal welding. Proceedings of the Institution of Mechanical Engineers, Part B: Journal of Engineering Manufacture 229: 16941710. DOI: $10.1177 / 0954405414538630$

3. Mendez, P. F., Barnes, N., Bell, K., et al. 2014. Welding processes for wear resistant overlays. Journal of Manufacturing Processes 16: 4-25. DOI: 10.1016/j.jmapro.2013.06.011

4. Olivares, E. A. G., and Díaz, V. M. V. 2018. Study of the hotwire TIG process with AISI-316L filler material, analysing the effect of magnetic arc blow on the dilution of the weld bead. Welding International 32: 139-148. DOI: 10.1080/09507116.2017.1347327

5. Borle, S. D., Le Gall, I., and Mendez, P. F. 2015. Primary chromium carbide fraction control with variable polarity SAW. Welding Journal 94(1): 1-s to 7-s.

6. Abed, H., Malek Ghaini, F., and Shahverdi, H. R. 2018. Characterization of Fe49Cr18Mo7B16C4Nb6 high-entropy hardfacing layers produced by gas tungsten arc welding (GTAW) process. Surface and Coatings Technology 352: 360-369. DOI: 10.1016/ j.surfcoat.2018.08.019

7. Sundaramoorthy, R., Tong, S. X., Parekh, D., and Subramanian, C. 2017. Effect of matrix chemistry and WC types on the performance of Ni-WC based MMC overlays deposited by plasma transferred arc (PTA) welding. Wear 376-377: 1720-1727. DOI: 10.1016/j.wear.2017.01.027

8. Günther, K., Bergmann, J. P., and Suchodoll, D. 2018. Hot wire-assisted gas metal arc welding of hypereutectic $\mathrm{FeCrC}$ hardfacing alloys: Microstructure and wear properties. Surface and Coatings Technology 334: 420-428. DOI: 10.1016/j.surfcoat.2017.11.059

9. AWS. 2005. Specification for Carbon Steel Electrodes and Rods for Gas Shielded Arc Welding.

10. Joseph, A., Harwig, D., Farson, D. F., and Richardson, R. 2003. Measurement and calculation of arc power and heat transfer efficiency in pulsed gas metal arc welding. Science and Technology of Welding and Joining 8: 400-406. DOI: 10.1179/136217103225005642

11. Xiang, T., Li, H., Wei, H. L., and Gao, Y. 2016. Effects of fill- ing status of cold wire on the welding process stability in twin-arc integrated cold wire hybrid welding. The International Journal of Advanced Manufacturing Technology 83: 1583-1593. DOI:

10.1007/s00170-015-7686-x

12. Gunter, K., Bergman, J. P., Zhang, C., Rosenberger, M., and Notni, G. 2018. Hot wire-assisted gas metal arc welding of Nibased hardfacing. Welding Journal 97(3): 99-s to 107-s. DOI: 10.29391/2018.97.009

13. Xiang, T., Li, H., Wei, H. L., and Gao, Y. 2016. Arc characteristics and metal transfer behavior of twin-arc integrated cold wire hybrid welding. The International Journal of Advanced Manufacturing Technology 87: 2653-2663. DOI: 10.1007/s00170-016-8663-8

14. Murray, P. E., and Scotti, A. 1999. Depth of penetration in gas metal arc welding. Science and Technology of Welding and Joining 4: 112-117. DOI: 10.1179/136217199101537644

15. Essers, W. G., and Walter, R. 1981. Heat transfer and penetration mechanisms with GMA and plasma-GMA welding. Welding Journal 60(2): 37-s to 42-s.

16. Rykalin, N. 1985. Asymptotic approximation of a heat conductivity problem with moving boundaries. Fiz. Khim. Obrab. Mater. 19: 28-31.

17. Mendez, P. F., Lu, Y., and Wang, Y. 2018. Scaling analysis of a moving point heat source in steady-state on a semi-infinite solid Journal of Heat Transfer 140: 081301. DOI: 10.1115/1.4039353

18. Wang, Y., Lu, Y., and Mendez, P. F. 2019. Scaling expressions of characteristic values for a moving point heat source in steady state on a semi-infinite solid. International Journal of Heat and Mass Transfer 135: 1118-1129. DOI: 10.1016/j.ijheatmasstransfer. 2019.02.042

19. Lancaster, J. F. 1986. The Physics of Welding, $2^{\text {nd }}$ ed. Oxford, UK: Pergamon Press.

20. Montgomery, D. C. 2012. Design and Analysis of Experiments, $8^{\text {th }}$ ed. New York, N.Y.: John Willey \& Sons, Chapter 6.

P. P. G. RIBEIRO, P. D. C. ASSUNÇÃO, and E. M. BRAGA are with the Metallic Materials Characterization Laboratory (LCAM), Federal University of Pará (UFPA), Belém - PA, Brazil. R. A. RIBEIRO (rdearauj@uwaterloo.ca) and A.P. GERLICH are with the Centre for Advanced Materials Joining (CAMJ), University of Waterloo, Waterloo, Ontario, Canada.

\section{AWS American Welding Society}

\section{Authors: Submit Research Papers Online}

Peer review of research papers is now managed through an online system using Editorial Manager software. Papers can be submitted into the system directly from the Welding Journal page on the AWS website (aws.org) by clicking on "submit papers." You can also access the new site directly at editorialmanager.com/wj/. Follow the instructions to register or log in. This online system streamlines the review process, and makes it easier to submit papers and track their progress. By publishing in the Welding Journal, more than 70,000 members will receive the results of your research.

Additionally, your full paper is posted on the American Welding Society website for FREE access around the globe. There are no page charges, and articles are published in full color. By far, the most people, at the least cost, will recognize your research when you publish in the world-respected Welding Journal. 